TEACHING AND LEARNING ETHICS

\title{
Empirical research in bioethical journals. A quantitative analysis
}

\author{
P Borry, P Schotsmans, K Dierickx
}

J Med Ethics 2006;32:240-245. doi: 10.1136/jme.2004.011478

\author{
See end of article for \\ authors' affiliations

..................... \\ Correspondence to: \\ Pascal Borry, Center for \\ Biomedical Ethics and Law, \\ $\mathrm{K}$ U Leuven, \\ Kapuciinenvoer 35/3, \\ 3000 Leuven, Belgium: \\ Pascal.Borry@med. \\ kuleuven.be \\ Received \\ 11 December 2004 \\ In revised form \\ 13 July 2005 \\ Accepted for publication \\ 15 July 2005
}

\begin{abstract}
Objectives: The objective of this research is to analyse the evolution and nature of published empirical research in the fields of medical ethics and bioethics.

Design: Retrospective quantitative study of nine peer reviewed journals in the field of bioethics and medical ethics (Bioethics, Cambridge Quarterly of Healthcare Ethics, Hastings Center Report, Journal of Clinical Ethics, Journal of Medical Ethics, Kennedy Institute of Ethics Journal, Nursing Ethics, Christian Bioethics, and Theoretical Medicine and Bioethics).

Results: In total, 4029 articles published between 1990 and 2003 were retrieved from the journals studied. Over this period, $435(10.8 \%)$ studies used an empirical design. The highest percentage of empirical research articles appeared in Nursing Ethics $(n=145,39.5 \%)$, followed by the Journal of Medical Ethics $(n=128,16.8 \%)$ and the Journal of Clinical Ethics $(n=93,15.4 \%)$. These three journals account for $84.1 \%$ of all empirical research in bioethics published in this period. The results of the $\chi^{2}$ test for two independent samples for the entire dataset indicate that the period 1997-2003 presented a higher number of empirical studies $(n=309)$ than did the period 1990-1996 $(n=126)$. This increase is statistically significant $\left(\chi^{2}=49.0264, p<.0001\right)$. Most empirical studies employed a quantitative paradigm $(64.6 \%, n=281)$. The main topic of research was prolongation of life and euthanasia $(n=68)$. Conclusions: We conclude that the proportion of empirical research in the nine journals increased steadily from $5.4 \%$ in 1990 to $15.4 \%$ in 2003 . It is likely that the importance of empirical methods in medical ethics and bioethics will continue to increase.
\end{abstract}

th $\mathrm{n}$ the last decade, an intense debate has challenged theologians, philosophers, healthcare scientists, social scientists, and medical scientists to clarify what value they attribute to empirical evidence in ethical reflection. ${ }^{1-3}$ At a fundamental level, this debate focuses on the regard that medical ethics holds for empirical approaches and, at a methodological level, it questions what this connection or integration between ethics and empirical research means in practice.

\section{STATE OF THE ART}

Notwithstanding the intense debate on the relationship between empirical and normative perspectives in bioethics, only two studies have described the evolution and nature of published empirical research in the fields of medical ethics and bioethics. ${ }^{45}$ Sugarman et $a l^{4}$ set out to describe the inclusion of empirical literature in the field of medical ethics during the 1980s. These authors used Bioethicsline (a database maintained by the National Reference Center for Bioethics, first issued in 1979), which was, at that time, the most comprehensive resource for identifying references of relevance to bioethics. Because Bioethicsline later was subsumed by Medline (Database from the National Library of Medicine, United States), Sugarman ${ }^{5}$ developed a new set of search criteria to identify empirical and ethics postings in the period 1980-1999 by using keywords and Boolean operators in Medline. This last study, however, presents serious shortcomings. Because the publications were not reviewed individually to ensure that they indeed represented a report of ethics or empirical research, it is likely that this research overestimates the number of truly relevant postings. Furthermore, this study retrieved no information about differences in journals, the respondents studied, and the methods used. ${ }^{5}$ In order to present an overview of the entire field of bioethics research and to report on a range of characteristics of that research and how they change over time, we have undertaken a new quantitative study for the period 1990-2003, with the aim of confronting the methodological shortcomings of the previous studies.

\section{OBJECTIVES}

By means of a quantitative study of peer reviewed journals in the fields of medical ethics and bioethics for the period 19902003, this article aims to examine four hypotheses concerning empirical research in bioethics.

Firstly, ever since Brody ${ }^{6}$ and Arnold and Forrow ${ }^{7}$ stated respectively that a novel form of scholarship in bioethics and a "new form of ethics paper" had appeared, various authors have claimed that ethicists' interest in empirical data continues to grow. ${ }^{8}$ As a consequence, our first objective is to analyse whether the number of empirical-ethical publications in selected peer reviewed journals in the field of bioethics and medical ethics really has been increasing and whether significant differences regarding this issue appear between these journals in the field of bioethics and medical ethics.

Secondly, we want to analyse the methods used in these empirical studies. Many commentators highlight the value of qualitative research methods for bioethics, which are said to be particularly well suited to understanding values, personal perspectives, experiences, and contextual circumstances. ${ }^{9}$ Some empirical scientists working in the field of bioethics state that the method par excellence for conducting socially and culturally cognisant and sensitive bioethical research is ethnography and its qualitative methodology. ${ }^{10-12}$ Thus, the second objective of our research is to assess whether this "positive" relationship between bioethics and the qualitative methodologies can be confirmed by a factual analysis.

Thirdly, we aim to identify the subjects of research in these empirical studies. The relationship between physicians, their 
patients, and society at large has undergone significant changes in recent times. The paternalistic relationship between physician and patient has-for example, been modified considerably in favour of the patient. ${ }^{13}$ Given the increasing attention to the autonomy and rights of the patient, it could be expected that more studies with patients than with healthcare providers would have been undertaken in the period we studied. After all, empirical research is one of the ways to hear and involve patients in the medical setting. As a result, the third objective of our study is to analyse the hypothesis that in the last decade patients were the most frequent subject of study in empirical research in bioethics.

Fourthly, we aim to determine the topics in bioethics that have been studied empirically. According to some estimates, less than $10 \%$ of the world's biomedical research and development funds are dedicated to addressing problems that are responsible for $90 \%$ of the world's burden of disease. ${ }^{14}$ Leigh Turner ${ }^{15}$ has also stated recently that the agenda of bioethicists is biased toward ethical problems that affect wealthy developed nations. He points out that bioethicists are reluctant to study important health issues facing people in poor countries and impoverished regions, instead addressing "sexy" topics, such as embryonic stem cell research, germline gene therapy, and therapeutic and reproductive cloning.

\section{METHODS}

Our research focuses on a set of peer reviewed journals (dating from 1990 to 2003) that are explicitly dedicated to bioethical issues in the context of health care and biomedicine and that are still active in 2003. The journals were selected after comparing the lists of journals indexed by Medline, Fangerau, ${ }^{16}$ the French Centre de documentation en éthique des sciences de la vie et de la santé de l'Institut National de la Santé et de la Recherche Médicale, and the German Reference Centre for Ethics in the Life Sciences. All research publications (excluding news, articles from the editors, interviews, letters, (invited) commentaries or (invited) replies to articles and cases) in peer reviewed journals indexed by the four databases were retrieved. This guaranteed that they were international journals. These journals were: Bioethics, Cambridge Quarterly of Healthcare Ethics, Hastings Center Report, Journal of Clinical Ethics, Journal of Medical Ethics, Kennedy Institute of Ethics Journal, Nursing Ethics, Christian Bioethics, and Theoretical Medicine and Bioethics. The two journals that were not present for the full period (1990-2003) in a Belgian library were not included in our analysis (HEC Forum and the Bulletin of Medical Ethics). Medline was used to obtain all electronic citations of the articles published in these journals. To verify their reliability, all journals were searched by hand and compared to the electronic dataset. Microsoft Access was used to create a template for data collection and coding. Articles were coded for the following criteria: number of authors; present occupation of author(s); countries of author(s); funding; research design; research subject, and research topic (in the case of empirical research). To guarantee reliability of data collection, the coding scheme was pilot tested by two independent researchers. Following a discussion to resolve inconsistencies, the coding scheme was refined and then used for our review of the entire dataset. An article was considered to include empirical research if there was evidence for collection and analysis of data. Hereby we understand the systematic investigation of a particular problem in the field of bioethics by using a research methodology (such as a qualitative or a quantitative approach) that has methodological roots in the social sciences with the aim to generate, analyse, and interpret reliable and valid information or data.
As we were studying journals in the fields of bioethics and medical ethics, we assumed that all articles were relevant for bioethical reflection. Both investigators subsequently judged each of the citations to determine whether they fitted our definition of empirical research in medical ethics, in terms of the method used and the subject of research. Any differences of opinion were discussed in order to come to a single interpretation. The abstract was used to code the article; in the event that the abstract did not reveal the information sought, the entire paper was subsequently retrieved and read. Data were analysed in SAS 9.1.2 using the non-parametric $\chi^{2}$ test for independent samples.

\section{RESULTS}

\section{Prevalence of empirical research in bioethics}

In total, 4029 articles published between 1990 and 2003 were retrieved from the nine bioethical journals under study. As we can observe in table 1 , over this period of time, 435 $(10.8 \%)$ studies used an empirical design. In 3594 articles $(89.2 \%)$ there was no evidence of data collection and analysis. The period studied shows an increase in the number of publications with an empirical design. Although only 5.4\% of the total number of publications indexed in 1990 were empirical, they amounted to $15.3 \%$ in 2003 . The results of the $\chi^{2}$ test for two independent samples for the entire dataset (table 2) indicate that the period 1997-2003 presented a higher number of empirical studies $(n=309)$ than did the period 1990-1996 $(\mathrm{n}=126)$. This increase is statistically significant $\left(\chi^{2}=49.0264, \mathrm{p}<.0001\right)$.

\section{Choice of journal}

Table 1 shows that the highest percentage of empirical research articles appeared in Nursing Ethics ( $\mathrm{n}=145,39.5 \%$ of the publications in this journal), followed by the Journal of Medical Ethics $(\mathrm{n}=128,16.8 \%)$ and the Journal of Clinical Ethics $(\mathrm{n}=93,15.4 \%)$. These three journals together account for $84.13 \%$ of all empirical research in bioethics published from 1990 to 2003 in the nine selected journals.

On the other hand, some journals rarely or never published empirical research over this period-for example the Hastings Center Report ( $\mathrm{n}=5,0.9 \%$ of the publications in this journal), Kennedy Institute of Ethics Journal $(\mathrm{n}=3,1 \%)$, and Christian Bioethics $(\mathrm{n}=0,0 \%)$. Figure 1 shows that the increase in articles with an empirical research design is most noticeable in Nursing Ethics. At the time of this journal's inception in 1994, it counted $12.5 \%$ of empirical publications in its journal $(\mathrm{n}=3)$, while in 2003 , it counted $60 \%(\mathrm{n}=27)$ of empirical publications. Because Nursing Ethics clearly seems to influence the evolution of the number of empirical studies in our dataset, we compared the results of a $\chi^{2}$ test with and without this journal (table 2). The dataset without Nursing Ethics still presents significantly more empirical studies in the period 1997-2003 $(\mathrm{n}=186)$ than from 1990-1996 $(\mathrm{n}=104)$, but has a lower $\chi^{2}$ value $\left(\chi^{2}=15,4169, \mathrm{p}<.0001\right)$.

\section{Choice of paradigm and data collection method}

As we can see in table 3, most empirical studies employed a quantitative paradigm $(\mathrm{n}=281,64.6 \%)$. The proportion of articles based on a qualitative design was $32.2 \%(n=140)$. A minority combined quantitative and qualitative paradigms $(3.2 \%, \mathrm{n}=14)$. Of all empirical studies, more than half of the articles with a qualitative design were published in Nursing Ethics $(\mathrm{n}=74,52.9 \%)$. More than half of the articles with a quantitative design were published in the Journal of Medical Ethics and the Journal of Clinical Ethics ( $\mathrm{n}=170,60.5 \%$ ). As we can observe in table 3, more than half of the empirical studies used a descriptive survey $(n=233,53.56 \%)$, which typically sought to ascertain respondents' perspectives or experiences with a specified subject in a predetermined structured 
Table 1 Prevalence of publications with an empirical research design published per year in each journal, in absolute numbers and as a percentage of total

\begin{tabular}{|c|c|c|c|c|c|c|c|c|c|c|c|c|c|c|c|c|}
\hline \multirow[b]{2}{*}{ Journal } & \multicolumn{14}{|c|}{ Year } & \multirow[b]{2}{*}{ Total } & \multirow[b]{2}{*}{ Total \% } \\
\hline & 90 & 91 & 92 & 93 & 94 & 95 & 96 & 97 & 98 & 99 & 00 & 01 & 02 & 03 & & \\
\hline Bioethics & 4 & 1 & 0 & 2 & 0 & 0 & 1 & 1 & 2 & 1 & 2 & 4 & 1 & 3 & 22 & 6.6 \\
\hline $\begin{array}{l}\text { Cambridge Quarterly } \\
\text { of Healthcare Ethics } \\
\text { (starts in 1992) }\end{array}$ & NA & NA & 1 & 3 & 2 & 1 & 2 & 6 & 0 & 2 & 3 & 1 & 3 & 3 & 27 & 5.6 \\
\hline Hastings Center Report & 0 & 1 & 1 & 1 & 0 & 0 & 1 & 1 & 0 & 0 & 0 & 0 & 0 & 0 & 5 & 0.9 \\
\hline Journal of Clinical Ethics & 4 & 5 & 4 & 11 & 6 & 5 & 4 & 13 & 9 & 7 & 9 & 7 & 5 & 4 & 93 & 15.4 \\
\hline Journal of Medical Ethics & 2 & 1 & 4 & 5 & 6 & 6 & 13 & 11 & 10 & 15 & 15 & 14 & 12 & 14 & 128 & 16.8 \\
\hline $\begin{array}{l}\text { Kennedy Institute of Ethics } \\
\text { journal (starts in 1991) }\end{array}$ & NA & 0 & 1 & 0 & 0 & 1 & 0 & 0 & 0 & 0 & 1 & 0 & 0 & 0 & 3 & 1 \\
\hline $\begin{array}{l}\text { Nursing Ethics (starts in } \\
1994 \text { ) }\end{array}$ & NA & NA & NA & NA & 3 & 8 & 11 & 11 & 12 & 17 & 14 & 16 & 26 & 27 & 145 & 39.5 \\
\hline $\begin{array}{l}\text { Christian Bioethics } \\
\text { (starts in 1995) }\end{array}$ & NA & NA & NA & NA & NA & 0 & 0 & 0 & 0 & 0 & 0 & 0 & 0 & 0 & 0 & 0 \\
\hline $\begin{array}{l}\text { Theoretical Medicine } \\
\text { and Bioethics }\end{array}$ & 0 & 1 & 0 & 2 & 1 & 1 & 0 & 0 & 0 & 2 & 0 & 0 & 3 & 2 & 12 & 3.2 \\
\hline Total & 10 & 9 & 11 & 24 & 18 & 22 & 32 & 43 & 33 & 44 & 44 & 42 & 50 & 53 & 435 & \\
\hline Total \% & 5.4 & 4.9 & 5.1 & 8.8 & 5.8 & 6.5 & 10.7 & 14.2 & 11.7 & 13.5 & 14.2 & 12.5 & 15.6 & 15.4 & & 10.8 \\
\hline
\end{tabular}

manner at a single point in time (by self administered questionnaire or structured [telephone] interview). Other, much less frequent, quantitative methods included longitudinal surveys $(n=13,3 \%)$, which followed a group of respondents over time; (observational) prospective studies $(\mathrm{n}=15,3.5 \%)$, which observed interaction and quantified particular behaviours; and (observational) retrospective studies $(n=11,2.5 \%)$, based on a quantitative study of materials, such as patient records, public documents, informed consent forms, etc. The most frequently used qualitative research method was the in depth interview ( $\mathrm{n}=89,20.5 \%)$.

\section{Sources of data}

The bioethical empirical research that we analysed drew on a wide variety of data sources (table 4 ). The sources cited most frequently were nursing staff $(\mathrm{n}=98,22.5 \%)$, patients $(\mathrm{n}=97,22.3 \%)$, and physicians $(\mathrm{n}=92,22.1 \%)$. Some groups were much more likely to be the subject of quantitative research than of qualitative research, such as the general public $(21$ hits in quantitative research, 0 in

Table 2 Prevalence of research publications with an empirical design during the first and second halves of the period studied

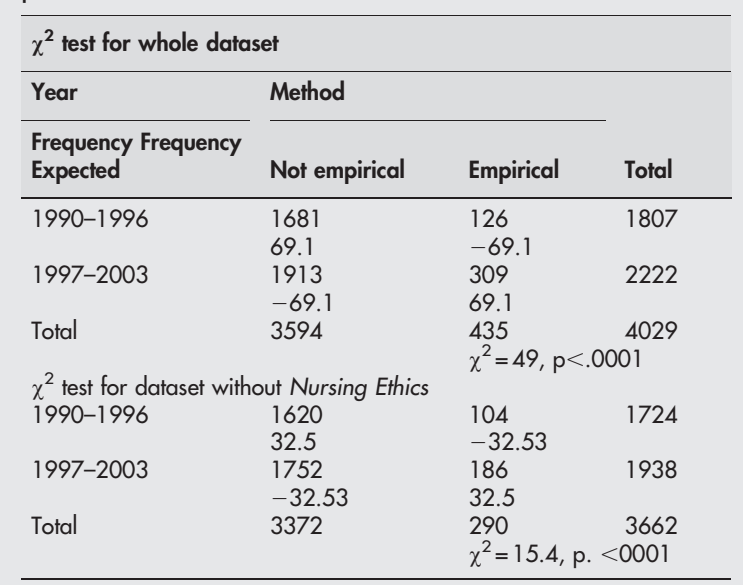

qualitative research: 21/0; this represents $7.5 \%$ of the publications with a quantitative design and $0 \%$ of the publications with a qualitative design); students (41/2; $14.6 \% v 1.4 \%)$; ethicists and ethics committees $(22 / 2 ; 7.8 \% v$ $1.4 \%)$, and physicians $(71 / 19 ; 25.3 \% v 13.6 \%)$. Nursing staff $(54 / 40 ; 19.2 \% \vee 28.6 \%)$ and patients $(61 / 35 ; 21.7 \%$ v $25 \%)$ have been studied more in publications with a qualitative design.

\section{Choice of research topic}

The publication's abstract was used to classify its main research topic as well as second and third topic if appropriate. Our classification system was based on a refined version of the library classification scheme of the National Reference Center for Bioethics Literature. ${ }^{1}$ Thirty three topics were identified in the published research, as depicted in table 5. The main topic of research was prolongation of life and euthanasia ( $\mathrm{n}=68$ - for example, artificial feeding, DNR orders, persistent vegetative state, euthanasia), closely followed by theoretical perspectives on ethics and bioethics ( $\mathrm{n}=58$-for example, sensitivity to and identification of ethical problems, ethical reasoning) and informed consent and patient participation in decision making $(n=42-$ for example, informed consent in general, parental consent, competence, or substituted judgment). These three main

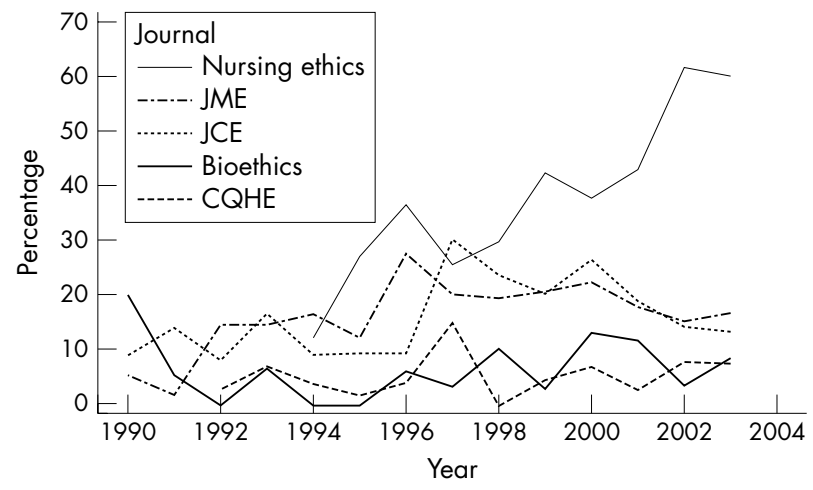

Figure 1 Percentage of publications with an empirical design, by publication year and by journal (with in total more than $5 \%$ of empirical publications [see also table 1]). 
Table 3 Prevalence of publications using a qualitative or quantitative research paradigm, in absolute numbers and as a percentage of total empirical publications

\begin{tabular}{lcc}
\hline Method & Frequency & $\%$ \\
\hline Quantitative & 281 & 64.6 \\
Descriptive survey & 233 & 53.6 \\
Longitudinal prospective survey & 13 & 3 \\
Observational prospective study & 15 & 3.5 \\
Observational retrospective study & 11 & 2.5 \\
Other quantitative & 9 & 2.1 \\
Qualitative & 140 & 32.2 \\
Interviews & 89 & 20.5 \\
Content analysis & 11 & 2.5 \\
Focus group & 16 & 3.7 \\
Participant observation & 20 & 4.6 \\
Other qualitative & 4 & 0.9 \\
Combination of qualitative and quantitative & 14 & 3.2 \\
design & & \\
Descriptive survey \& content analysis & 3 & 0.7 \\
Descriptive survey \& interviews & 8 & 1.8 \\
Other combination of quantitative and & 3 & 0.7 \\
qualitative methods & & \\
Total & 435 & 100 \\
\hline
\end{tabular}

topics remained dominant when the second and third topics of research were included.

\section{DISCUSSION}

Sugarman et $\mathrm{al}^{4}$ observed that during the 1980s, on average $3.4 \%$ of the 663 postings retrieved from Bioethicsline were based on empirical research. The proportion of empirical research in the total postings increased steadily from $1.5 \%$ in 1980 to over 5\% in 1989. Even though our dataset is not the same, our results match those of Sugarman et al's study remarkably well. In 1990, we observed a total of $5.4 \%$ of empirical postings, which increased steadily to $15.4 \%$ in 2003. Overall, the prevalence of empirical research articles in the field of bioethics increased gradually from 1980 until 2003. Our research shows that the hypothesis of Sugarman's second study-that empirical research in ethics represents approximately $25 \%$ of these postings-overestimates the

1 http://www.georgetown.edu/research/nrcbl/nrc/index.htm (last accessed 21 Jun 2005). number of empirical postings in the field of bioethics and medical ethics.

We observed differences, however, among the journals studied. Three journals accounted for more than $80 \%$ of the empirical publications: significantly more articles with an empirical design were accepted for publication in Nursing Ethics, the Journal of Clinical Ethics, and the Journal of Medical Ethics. The 1997 change in the notice for contributors to the Journal of Medical Ethics is noteworthy. For the first time, the editors issued guidelines for submitting reports based on empirical research.

From 1980 until 2003, the number of empirical publications in journals of bioethics and medical ethics increased steadily. It is not clear, however, whether this emergence reflects the fact that journals in bioethics and medical ethics were more disposed to publish empirical studies or the fact that more ethics related empirical studies were realised and submitted in general (and were reported more frequently in journals of medical ethics and bioethics as a consequence). Our sample was limited to international peer reviewed periodicals dedicated to medical ethics and bioethics. It would be interesting to include an overview of the number, design, and topic of empirical studies in bioethics and medical ethics that have been published in all medical journals. This would not be easy, however, considering the difficulty of identifying ethics related empirical studies in journals that are not typically ethics related, and the sheer number of medical journals in circulation.

On the basis of the increase observed in this study in both the absolute number of empirical/ethical studies and the proportion of these studies compared to the total number of bioethics papers, we advance the hypothesis that more ethics related empirical studies are carried out and reported. The increase in empirical studies confirms previous research ${ }^{17}$ that medical ethics and bioethics as a field and the journals in this field are more open to empirical approaches than in years past. In that study we described (a) how a theory driven bioethics that did not sufficiently take practical reality into account has been criticised, (b) how clinical ethics has increased the awareness of empirical research in bioethics, and (c) how the paradigm of evidence based approaches has been taken up by the vocabulary of bioethics. This has certainly led to a greater openness toward empirical studies in bioethics on the part of several institutes for medical ethics

Table 4 Frequency and percentage of subjects that have been studied in publications with an empirical, quantitative, and/or qualitative design

\begin{tabular}{|c|c|c|c|c|c|c|c|c|}
\hline Frequency & \% Emp Publ & N Emp Publ & \% Quant & N Quant & \% Qual & Qual & $\%$ Comb & N Comb \\
\hline Nursing staff & $22.5 \%$ & 98 & $19.2 \%$ & 54 & $28.6 \%$ & 40 & $28.6 \%$ & 4 \\
\hline Patients & $22.3 \%$ & 97 & $21.7 \%$ & 61 & $25 \%$ & 35 & $7.1 \%$ & 1 \\
\hline Physicians & $21.1 \%$ & 92 & $25.3 \%$ & 71 & $13.6 \%$ & 19 & $14.3 \%$ & 2 \\
\hline Students & $10.6 \%$ & 46 & $14.6 \%$ & 41 & $1.4 \%$ & 2 & $21.4 \%$ & 3 \\
\hline $\begin{array}{l}\text { Ethicists \& ethics } \\
\text { committees }\end{array}$ & $5.7 \%$ & 25 & $7.8 \%$ & 22 & $1.4 \%$ & 2 & $7.1 \%$ & 1 \\
\hline General public & $4.8 \%$ & 21 & $7.5 \%$ & 21 & $0 \%$ & 0 & $0 \%$ & 0 \\
\hline Caregivers & 4.4 & 19 & $3.9 \%$ & 11 & $5 \%$ & 7 & $7.1 \%$ & 1 \\
\hline Relatives of patients & $4.1 \%$ & 18 & $2.8 \%$ & 8 & $5.7 \%$ & 8 & $14.3 \%$ & 2 \\
\hline Parents & $3 \%$ & 13 & $1.8 \%$ & 5 & $5.7 \%$ & 8 & $0 \%$ & 0 \\
\hline $\begin{array}{l}\text { Responses to open ended } \\
\text { questions }\end{array}$ & $2.8 \%$ & 12 & $0 \%$ & 0 & $6.4 \%$ & 9 & $21.4 \%$ & 3 \\
\hline Women & $2.5 \%$ & 11 & $1.1 \%$ & 3 & $5.7 \%$ & 8 & $0 \%$ & 0 \\
\hline Minors & $2.3 \%$ & 10 & $0.7 \%$ & 2 & $5.7 \%$ & 8 & $0 \%$ & 0 \\
\hline Patient records & $2.3 \%$ & 10 & $3.6 \%$ & 10 & $0 \%$ & 0 & $0 \%$ & 0 \\
\hline Population groups & $1.8 \%$ & 8 & $1.1 \%$ & 3 & $3.6 \%$ & 5 & $0 \%$ & 0 \\
\hline Teaching staff & $1.6 \%$ & 7 & $2.1 \%$ & 6 & $0.7 \%$ & 1 & $0 \%$ & 0 \\
\hline Research personnel & $1.4 \%$ & 6 & $2.1 \%$ & 6 & $0 \%$ & 0 & $0 \%$ & 0 \\
\hline Hospital administrators & $1.1 \%$ & 5 & $1.1 \%$ & 3 & $0.7 \%$ & 1 & $7.1 \%$ & 1 \\
\hline Other & $9.7 \%$ & 42 & $6.8 \%$ & 19 & $15 \%$ & 21 & $14.3 \%$ & 2 \\
\hline Total & & 540 & & 346 & & 174 & & 20 \\
\hline
\end{tabular}

Some publications studied more than one subject. As a consequence, percentages will be higher than $100 \%$. 


\begin{tabular}{|c|c|c|}
\hline Topic & 1st topic & 2nd and 3rd topic \\
\hline Prolongation of life and euthanasia & 68 & 4 \\
\hline Ethics and bioethics: theoretical perspectives & 58 & 14 \\
\hline Informed consent and patient participation in decisions making & 42 & 12 \\
\hline Ethics education & 34 & 1 \\
\hline Ethics committees and ethics consultation & 30 & 0 \\
\hline Patient relationships & 19 & 5 \\
\hline Economics of health care and allocation of healthcare resources & 17 & 3 \\
\hline Quality of health care & 17 & 2 \\
\hline Health care for newborn, children, and minors & 16 & 15 \\
\hline Truth telling and the right not to know & 13 & 2 \\
\hline Artificial and transplanted organs/tissue & 12 & 2 \\
\hline Living wills and advance directives & 12 & 4 \\
\hline Health care for the aged & 10 & 3 \\
\hline Human experimentation & 10 & 12 \\
\hline Care for the dying patient & 9 & 2 \\
\hline Professional misconduct and malpractice & 9 & 4 \\
\hline Confidentiality and privacy & 8 & 3 \\
\hline Abortion & 6 & 0 \\
\hline Sexuality and gender & 5 & 3 \\
\hline Genetic testing and screening & 5 & 1 \\
\hline Quality of life & 5 & 1 \\
\hline Health care for mentally disabled persons & 4 & 4 \\
\hline Health care for minority groups & 4 & 4 \\
\hline Suicide and assisted suicide & 4 & 6 \\
\hline Genetics, molecular biology, and microbiology, general & 3 & 1 \\
\hline Death and dying, general & 3 & 0 \\
\hline Aids and HIV & 2 & 4 \\
\hline Right to refuse treatment & 1 & 1 \\
\hline Health care for women & 1 & 1 \\
\hline Reproduction and reproductive technologies, general & 1 & 0 \\
\hline Genetic modification & 1 & 0 \\
\hline International/political dimensions of biology and medicine & 1 & 1 \\
\hline Social control of science and technology & 1 & 0 \\
\hline Other & 4 & 0 \\
\hline
\end{tabular}

and [in] some editorial boards of journals in the fields of bioethics and medical ethics.

In Sugarman et al's research, ${ }^{4}$ only a small minority of the empirical studies in the period 1980-1989 used a qualitative design $(\mathrm{n}=18,3 \%)$. By contrast, our research for the period 1990-2003 revealed a proportion of $32.2 \%(n=140)$ for qualitative studies. More than half of these studies appeared in Nursing Ethics. This remarkable growth in the number of qualitative studies was caused partially by the fact that qualitative studies are increasingly recognised as important to understanding the richness and complexities of health care. $^{18}$ The discipline of nursing made a particularly important contribution to the high proportion of qualitative studies. In a quantitative evaluation of the qualitative studies published in 170 core clinical journals during 2000, McKibbon and Gadd ${ }^{19}$ showed that most qualitative studies were published in nursing journals and only rarely in high ranked medical and clinical journals. Qualitative studies have been embraced in nursing research and practice. ${ }^{19}$ When confronted recently by proponents of evidence based movements, some nursing scholars argued strongly for nursing to defend the importance of qualitative research. ${ }^{20}$ It is not surprising that nursing ethics espouses significantly more qualitative research. ${ }^{21}$ As a result, the substantial number of qualitative studies is not representative of bioethics and medical ethics in general, but reflects the methodological inclination of research in the field of nursing sciences. ${ }^{22}$

Although we expected an overwhelming presence of patients as research subject, as was observed already by Sugarman et al in 1980, ${ }^{4}$ our research shows an almost equal division of responses from nursing staff, patients, and physicians. Contrary to what we expected, patients are not the most studied group in empirical research in the field of medical ethics and bioethics. Healthcare professionals (nursing staff, physicians, and caregivers) are much more studied than patients, probably because they can be more easily studied as group-that is, they are more accessible for researchers in the field of health care.

With regard to the topic of research, ethical problems related to the end of life have been the most common subject of study: these include prolongation of life and euthanasia $(n=68)$; living wills and advance directives $(n=12)$; health care for the aged $(n=10)$; care for the dying patient $(n=9)$; (assisted) suicide $(\mathrm{n}=4)$, and death and dying in general $(\mathrm{n}=3)$. In addition, a great deal of research concerns problems and issues that deal with ethics as a profession and discipline, such as theoretical perspectives on ethics and bioethics $(n=58)$, ethics committees and ethics consultation $(\mathrm{n}=30)$, and ethics education $(\mathrm{n}=34)$. In fact, empirical studies in bioethics commonly address ethical issues that arise in wealthy developed countries, while problems that are more relevant to developing countries-international justice and human rights; HIV and AIDS; health care for minorities; population growth; world hunger; patents; basic health care; food; safe water, and sanitation-are only rarely studied empirically. An explanation might be that some topics are difficult or less useful to study empirically. Future research is needed to map all the different topics studied in the field of bioethics and medical ethics. This epidemiology of bioethics ${ }^{23}$ could indicate the degree to which bioethics is biased toward some ethical issues and neglects other relevant topics of study.

\section{CONCLUSION}

In the nine peer reviewed journals from the field of bioethics and medical ethics, we observed a clear emergence of 
empirical research. The nine journals were chosen on the basis that they were present in the four databases listed. Important journals, however, such as the American Journal of Bioethics, the Journal of Medicine and Philosophy, Developing World Bioethics, Ethics and Medicine, Medicine Health Care and Philosophy did not fit our selection criteria and were excluded from analysis. Although we did not intentionally limit our research to English language journals, journals as Ethik in der Medizin and other non-English language journals could not be included for the same reason. Further research should address our research objectives in this larger group of journals.

Furthermore, ethics related empirical research is published in other medical journals, which number over 40,000 worldwide. ${ }^{24}$ Future research should address the presence and characteristics of empirical research in bioethics and medical ethics in the contexts of these publications.

Empirical research is an accepted and growing component of the medical ethics and bioethics literature. We believe that bioethics could benefit significantly from intense discussion and interaction between the empirical and normative perspectives. The two perspectives should interact with and learn from each other, in spite of their different backgrounds and characteristics. Reflecting on the relationship between empirical and normative perspectives is a fundamental issue that has implications for defining research priorities; applying for grants; teaching bioethics to students, and being involved in ethical decision making. It is likely that the importance of empirical methods in medical ethics and bioethics can only be expected to increase.

\section{ACKNOWLEDGEMENTS}

The authors wish to thank Professor Dr Heiner Fangerau for providing the list of journals on medical ethics that he developed in his study and Eveline de Vos for her help in the data collection.

\section{Authors' affiliations}

P Borry, P Schotsmans, K Dierickx, Center for Biomedical Ethics and Law, K U Leuven, Leuven, Belgium

\section{REFERENCES}

1 Hope T. Empirical medical ethics. J Med Ethics 1999;25:219-20.

2 Borry P, Schotsmans P, Dierickx K. What is the contribution of empirical research in bioethics? An ethical analysis. Med Health Care Philos 2004;7:41-53.

3 Holm S, Jonas M. Engaging the world. The use of empirical research in bioethics and the regulation of biotechnology. Amsterdam: IOS Press, 2004

4 Sugarman J, Faden R, Weinstein J. A decade of empirical research in medical ethics. In: Sugarman J, Sulmasy D, eds. Methods in medical ethics. Washington, DC: Georgetown University Press, 2001:19-28.

5 Sugarman J. The future of empirical research in bioethics. J Law Med Ethics 2004:32:226-31.

6 Brody BA. Quality of scholarship in bioethics. J Med Philos 1990;15:161-78.

7 Arnold R, Forrow L. Empirical research in medical ethics: an introduction. Theor Med 1993; 14:195-6.

8 Molewijk AC. Integrated empirical ethics: in search for clarifying identities. Med Health Care Philos 2004;7:85-7.

9 Hull SCH, Taylor HA, Kass NE. Qualitative methods. In: Sugarman J, Sulmasy D, eds. Methods in medical ethics. Washington, DC: Georgetown University Press, 2001:147-68.

10 Gallagher EB, Schlomann P, Sloan RS, et al. To enrich bioethics, add one part social to one part clinical. In: De Vries R, Subedi J, eds. Bioethics and society. Constructing the ethical enterprise. New Jersey: Prentice Hall, 1998:166-91.

11 Jennings B. Ethics and ethnography in neonatal intensive care. In: Weisz G, eds. Social sciences perspectives on medical ethics. Dordrecht: Kluwer, 1990:261-72.

12 Fox RC, de Vries R. Afterword: the sociology of bioethics. In: de Vries R, Subedi J, eds. Bioethics and society. Constructing the ethical enterprise. New Jersey: Prentice Hall, 1998:270-6.

13 World Medical Association. World Medical Association declaration on the rights of the patient. Ferney-Voltaire: WMA, 1995.

14 Attaran A. Human rights and biomedical research funding for the developing world: covering state obligations under the right to health. Health Hum Rights 1999;4:26-58.

15 Turner L. Bioethics needs to rethink its agenda. BMJ 2004;328:175.

16 Fangerau $\mathrm{H}$. Finding European bioethical literature: an evaluation of the leading abstracting and indexing services. J Med Ethics 2004;30:299-303.

17 Borry P, Schotsmans P, Dierickx K. The birth of the empirical turn in bioethics. Bioethics 2005; 19:49-71.

18 Hoff TJ, Witt LC. Exploring the use of qualitative methods in published health services and management research. Med Care Res Rev 2000;57:139-60.

19 McKibbon KA, Gadd CS. A quantitative analysis of qualitative studies in clinical journals for the 2000 publishing year. BMC Med Inform Decis Mak 2004;4:11.

20 Rolfe G. Faking a difference: evidence based nursing and the illusion of diversity. Nurse Educ Today 2002;22:3-12.

21 Rolfe $\mathbf{G}$. Insufficient evidence: the problems of evidence based nursing. Nurse Educ Today 1999; 19:433-42.

22 Gardner G. The nurse researcher: an added dimension to qualitative research methodology. Nurs Inq 1996:3:153-8.

23 Fetters MD, Brody H. The epidemiology of bioethics. J Clin Ethics 1999;10:107-15.

24 Wyatt JC. Reading journals and monitoring the published work. J R Soc Med 2000;93:423-7. 